\title{
Unilateral segmental Darier disease following Blaschko lines: A case report
}

\author{
César Bimbi ${ }^{1,2}$, Piotr Brzezinski ${ }^{3}$, Katarzyna Borowska ${ }^{4}$
}

${ }^{1}$ Dermatological Comittee of State Medical Council of Rio Grande do Sul Brazil, ${ }^{2}$ Brazilian Society of Dermatology, ${ }^{3}$ Institute of Biology and Environmental Protection, Pomeranian Academy, Slupsk, Poland, ${ }^{4}$ Department of Histology and Embryology with Experimental Cytology Unit, Medical University of Lublin, Lublin, Poland

Corresponding author: Dr. César Bimbi, E-mail: cbimbi@terra.com.br

\begin{abstract}
Darier disease is an autosomal-dominant disorder of keratin production which leads to a loss in epithelial adhesion and abnormal keratinization. The clinical correspondence is keratotic papules grouped in sebaceous areas of trunk, scalp, forehead and flexures. It is a rare disease and the variant focused on here of unilateral segmental distribution following the lines of Blaschko is rarer still, considering the fact that this presentation counts for only $10 \%$ of this already uncommom disease and with only 40 cases being reported in English medical literature. Mutation in this gene is expressed in the skin and brain. The treatment of Darier disease can be challenging and is often difficult and sometimes unsatisfactory. Systemic retinoids are considered the drug of choice for treating Darier disease. However, their use is limited by potential side effects. We described the case a metalworker male with unilateral segmental Darier disease following Blaschko lines and we review the literature on this subject.
\end{abstract}

Key words: Darier’s disease; Blaschko lines; Unilateral segmental

\section{INTRODUCTION}

Darier disease (DD) also called 'Darier-White disease' is a rare slowly progressive genetic skin disorder characterized by multiple keratotic papules. There is a loss of adhesion and an inadequate binding between epidermal cells caused by mutations in the gene mapped onto a single locus on chromosome 12q23-q24, which encodes a sarco/endoplasmic reticulum calcium ATPase pump (SERCA2) [1]. This gene is responsible for calcium transport into cells. Penetrance is high but expressivity is variable so, if a patient is greatly affected it does not necessarily mean that other members will get this severe disease [2,3]. The gene is expressed also in the brain [4]. DD begins in childhood and affects men and women the same. Clinically its classical form shows yellow-brown hyperkeratotic rough papules that coalesce into warty plaques on central trunk, scalp, forehead, and flexures, in a way simulating seborrhea. Abnormal keratinocyte adhesion and aberrant epidermal keratinization are the primary histologic features also with suprabasilar splitting and villus-like structures in the dermis. Dyskeratosis is demonstrated by corps-rounds and grains with overlying hyperkeratosis.

\section{CASE REPORT}

A 59-year-old metalworker male attended our clinic with a right-sided skin eruption, which he noted when he was 16 years old. No family members had similar conditions. The eruption was pruritic and returned almost every summer. Reddish-brown dirty-coloured keratotic papules with greasy appearance spread in a swirling distribution along the Blaschko lines beginning on the anterior surface of the right thigh, the lateral surface of the right knee and the anterior e lateral surfaces of the right leg (Fig. 1). Also, on the lateral and posterior surfaces of the right arm, from the deltoid region to a few inches above the elbow (Fig. 2). It was often exacerbated by repeated periods of heat 
and sweating, in a recurring pattern. No other skin lesions were detected. Nails and oral cavity were within normal aspects. Hypertension and high cholesterol levels were observed on his exams. There was no past medical history, family history, or prior treatment for this condition. A biopsy revealed hyperkeratosis with parakeratosis, acanthosis, mild papillomatosis and acantholytic dyskeratosis with acantholysis resulting in suprabasilar clefting with corps ronds (Fig. 3).

\section{DISCUSSION}

Two types of DD show linear distribution. The case reported here is type 1 - DD following Blaschko lines in unilateral distribution. In Type 2 these lines of lesions overlap to disseminated DD [5]. Clinical variations of DD are hypertrophic, linear, zosteriform and vesiculobullous. Blaschko lines are pathways of epidermal cell migration and proliferation that happens during the development of the fetus and there is no dermatomal or lymphatic configurations. Some authors have named localized DD as " zosteriform " but in fact patients with this form of DD demonstrates a Blaschkoid-not dermatomal-distribution. Blaschkoid distribution of lesions on normal skin, reflects heterozygosity for a postzygotic somatic mutation during early embryogenesis [6]. The prevalence of DD in individuals has been estimated to be from 1 in 55,000 to 1 in 100,000 . It has been estimated that in $10 \%$ of DD cases, lesions are distributed following unilateral linear pattern. Kreibich in 1906 first observed DD in a localized pattern. Since then, other cases occasionally have been published totaling 40 cases to date in English medical literature [5]. The first signs of the generalized condition usually appear in patients between the ages of 6 and 20 years. The age of onset of unilateral variant DD is later, between the second and fourth decades, with the average age being 27 years. A negative family history is typical in unilateral cases.

It is debatable whether the psychological effects this disease are due solely to the fact of unpleasant presence of " smelly-dirty " cutaneous lesions. DD gene has pleiotropic effects in skin and brain. Both tissues share an ectodermal origin and intracellular calcium signaling in neurons is involved in neuronal excitability and neurotransmission [7]. There are numerous reports of cases of DD with neuropsychiatric disorders: epilepsy and depression [8]. Quality of life (QOL) questionnaires have shown that Darier's disease has a negative impact on patients depending on which skin

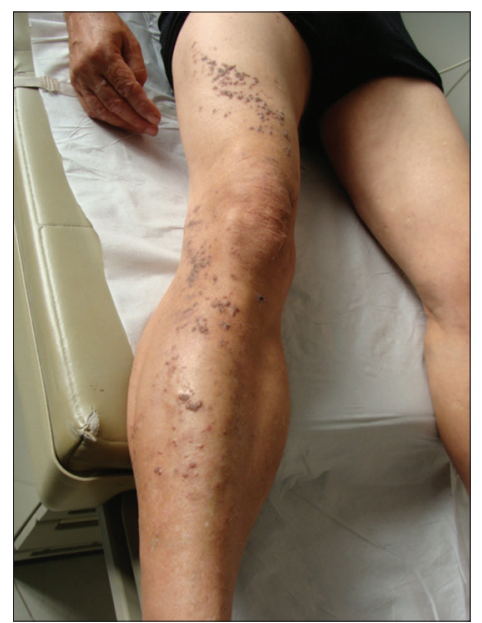

Figure 1: Keratotic papules in a swirling distribution along the Blaschko lines beginning on the anterior surface of the right thigh, lateral surface of the right knee and anterior e lateral surfaces of the right leg.

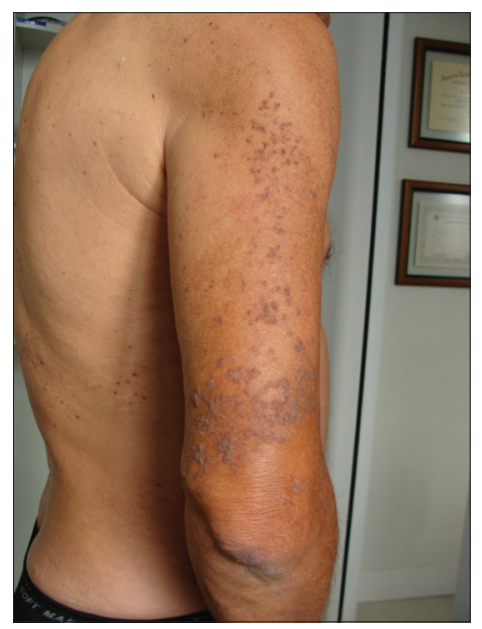

Figure 2: Keratotic papules grouped on lateral and posterior surfaces of the right arm, from the deltoid region to a few inches above the elbow.

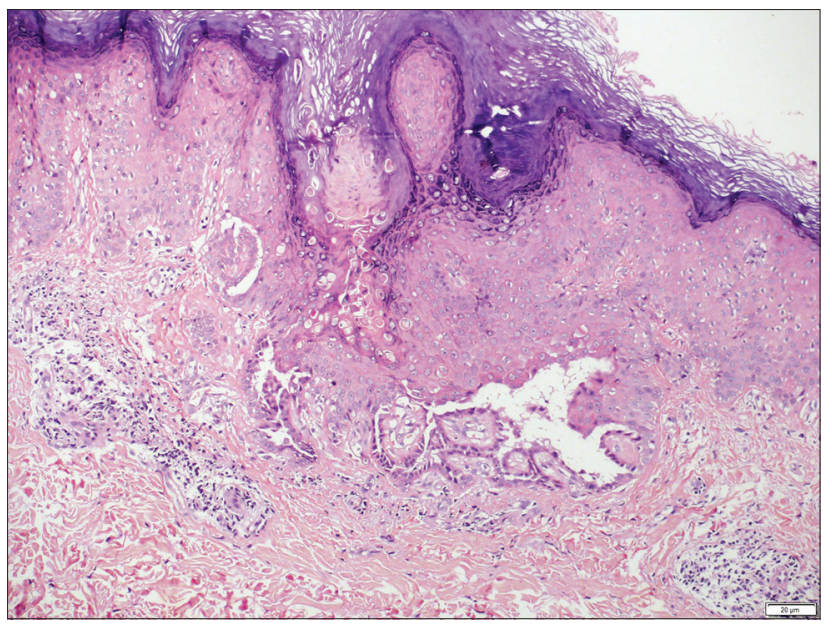

Figure 3: Suprabasal acantholysis, "corps-rounds" and superficial inflammatory perivascular infiltrate. (H\&Ex100). 
area is affected and clinical severity [9]. Most patients manage to lead a relatively normal life. The disease is often exacerbated by sun exposure, perspiration, friction and secondary infection. Cotton clothing, sun protection, reduced sweating, antiseptic bath solutions, antiseptic creams when bad odour occurs are simple recommendations that may be quite helpful $[3,10]$. In the case discussed here the hot work environment of a metallurgical industry may well have played a role in triggering the flares.

The efficacy of retinoids is based upon the fact that turnover rate of cells in DD is 7 times slower than normal rate and retinoids " speed " the descamation process. In our patient, we used oral retinoids which gave good results and left the option of topical retinoids for future flare ups since he had high cholesterol levels.

\section{REFERENCES}

1. Savignac M, Edir A, Simon M, Hovnanian A. Darier disease: a disease model of impaired calcium homeostasis in the skin. Biochim Biophys Acta. 2011;1813:1111-7.

2. Burge S. Darier's disease-clinical features and pathogenesis. Clin Exp Dermatol. 1994;19:193.
3. Darier's disease Patient Information Leaflets (PILs) British Association of Dermatologists (BAD) 2015.

4. Celik T, Celik U, Donmezer C, Komur M, Tolunay O, Demirtürk P. Cooccurrence of Darier's disease and epilepsy: a pediatric case report and review of the literature. Case Rep Pediatr. 2014;2014:831398.

5. Lavorato FG, Azulay-Abulafia L, Ramos V, Obadia DL, Rocha DS, Souza VF. Case for diagnosis: Linear Darier. An Bras Dermatol. 2013;88:656-8.

6. Griffiths WAD, Leigh IM, Judge MR. Disorders of keratinization. In: Champion RH, Burton JL Burns DA, et al, eds. Rook/ Wilkinson/Ebling Textbook of Dermatology. Oxford, England: Blackwell Scientific; 1998:1483-1588.

7. Baba-Aissa F, Raeymaekers L, Wuytack F, Dode L, Casteels R. Distribution and isoform diversity of the organellar Ca2+ pumps in the brain. Mol Chem Neuropathol. 1998;33:199-208.

8. Munro CS. The phenotype of Darier's disease: penetrance and expressivity in adults and children. Br J Dermatol. 1992;127:126-130.

9. Dodiuk-Gad R, Cohen-Barak E, Ziv M, Shani-Adir A, Amichai B, Zlotogorski A, et al. Health-related quality of life among Darier's disease patients. J Eur Acad Dermatol Venereol. 2013;27:51-6.

10. Pandey K, Gambhir ML, Malhotra SK. Bell's palsy in a case of Darier's disease - a rare disease association or coincidental finding? Our Dermatol Online. 2016;7:75-7.

Copyright by César Bimbi, et al. This is an open-access article distributed under the terms of the Creative Commons Attribution License, which permits unrestricted use, distribution, and reproduction in any medium, provided the original author and source are credited.

Source of Support: Nil, Conflict of Interest: None declared. 